\title{
Assessing the trend in sustainable remediation: a questionnaire survey of remediation professionals in various countries
}

\author{
Deyi Hou ${ }^{1^{\star}}$, Peter Guthrie ${ }^{2}$, Mark Rigby ${ }^{3}$ \\ ${ }^{1}$ School of Environment, Tsinghua University, Beijing, China 100084 \\ ${ }^{2}$ Centre for Sustainable Development, Department of Engineering, University of Cambridge, \\ Cambridge CB2 1PZ, UK \\ ${ }^{3}$ Parsons Corporation, South Jordan, Utah, 84095 USA \\ *Correspondence to: houdevi@tsinghua.edu.cn;
}

\section{ABSTRACT}

Over the past decade, sustainable remediation has grown from an emerging concept into a widely accepted new institutional norm. Scholar literature increased exponentially from nearly none in late 1990s to over 400 publications per year in 2014 . The present study used a questionnaire survey conducted in 2012 and 2014 to assess the global trend in the awareness and practice of sustainable remediation. A total of 373 responses were received from survey participants located in 22 countries. The survey found that the US and the UK similarly had the highest level of awareness and adoption rate of sustainable remediation. Asia and other developing countries had much lower awareness levels and/or adoption rates. For all regions, the adoption rates were significantly lower than awareness levels, indicating a large gap between awareness and practice. One specific example is regarding minimizing greenhouse gas emission, which is a focal point in sustainable remediation literature, but with very low adoption rate according to this survey. This study also found that the adoption rates of a few sustainable remediation considerations, such as "minimizing local scale secondary impact", "minimizing national to global scale secondary impact", and "bringing prosperity to disadvantaged community", had decreased between 2012 and 2014). On the other hand, the survey also suggests the remediation community has rendered more expertise, training, and resources in sustainable remediation between 2012 and 2014. The mixed results suggest that in order to enhance sustainable 
remediation adoption, it is imperative to employ continued effort to enhance the understanding of sustainable remediation by practitioners and to link self-interest and public interest with sustainable remediation considerations.

\section{KEYWORDS}

sustainable remediation; green remediation; contaminated land; questionnaire survey

\section{INTRODUCTION}

Contaminated sites are a huge liability in both developing and developed countries. In the United States (US), it was estimated that around 294,000 sites will require cleanup over the next 30 years (USEPA, 2004), including 9 million hectares of contaminated land overseen by the US Environmental Protection Agency (USEPA) (USEPA, 2010), and over 1,300 National Priority List sites (USEPA, 2013). In England and Wales, it was estimated that 300,000 hectares, or $2 \%$ of the land area of England and Wales, may be contaminated, including 781 identified "contaminated land" sites and 35 "special sites" (EA, 2009). In China, the land contamination issue is far more serious than what has been observed in western countries. According to the recent report from China's Ministry of Environmental Protection (MEP), 16.1\% of the nation's land has been polluted with contaminants ranging from arsenic and cadmium to polycyclic aromatic hydrocarbon and dichlorodiphenyldichloroethane (DDD) (MEP, 2014). These contaminated lands pose a risk to both human health and ecological systems.

While historically remediation focused on the removal and/or control of risks, there has been a recent shift towards sustainable practices within the remediation industry. sustainable remediation of contaminated sites has drawn much attention from governments, industry, and academia in recent years. Many white papers and technical guidance have been published by various organizations and government agencies (Ellis and Hadley, 2009; ITRC, 2011; CL:AIRE, 2010; USACE, 2010). Under 
the influence of such institutional forces, remediation professionals are motivated by public interest as well as self-interest to comply with new norms and rules (Hou and Al-Tabbaa, 2014; Prior, 2016). A number of academic studies have been published on issues like sustainability assessment, life cycle assessment (LCA) and sustainable technology development (Bardos, 2012; Bardos et al., 2011; Hou et al., 2014b; Madejón et al., 2011; Witters et al., 2012; ASTM, 2013). A search on Google Scholar indicates that the number of publications pertaining to sustainable remediation has grown exponentially over the last decade (see Figure 1).

Even though literature on sustainable remediation has grown substantially, there are research gaps in the sustainable remediation field which have impeded its adoption, due to an inability to quantify social and economic sustainability (Ellis and Hadley, 2009; ITRC, 2011) and tertiary impacts (Morais and Delerue-Matos, 2010), the lack of transferrable sustainability assessment results (Hou et al., 2014c), and the lack of understanding of practitioners' actual behavior (Hou et al., 2014a). It is also noted that there are country variations in research needs as stakeholders in some countries prefer to qualitative assessment rather than quantitative socioeconomic impact analysis. The actual behavior of remediation practitioners is of particular interest ; however, they are often driven more by socioeconomic and regulatory factors rather than technical factors. On the other hand, the reaction of decision makers to socioeconomic and regulatory constraints are subjective rather than objective. Therefore, it is necessary to study the behavior pattern of remediation practitioners in order to maximize the potential for sustainability in remediation. A better understanding in this arena can guide policy making, as well as technology development.

This study intends to examine the spatial and temporal variation in the adoption of sustainable remediation. Existing studies have shown that there are variabilities in the adoption of sustainable remediation practices among different countries (Hou et al., 2014a; Maurer, 2009). However, these studies are limited to a small number of 
countries. In addition, there is no comparison over time. The present study uses a questionnaire survey conducted in 2012 and 2014, with respondents from 22 countries, to conduct a spatial and temporal analysis. This study aims to provide an empirical assessment of the global trend in sustainable remediation, in order to provide insights on sustainable behavior, to researchers, policy makers, and practitioners.

\section{MATERIALS AND METHODS}

\subsection{Questionnaire Design}

A questionnaire survey was designed to gauge the adoption of sustainable behavior by remediation practitioners. Based on an extensive review of various sustainable remediation guidance documents, whitepapers, and policies (Ellis and Hadley, 2009; EURODEMO., 2007; ITRC, 2011; CL:AIRE, 2009; USACE, 2010; USEPA, 2008), a total of 27 sustainable behaviors were identified. These sustainable behaviors were identified based on the following criteria: 1 ) they are mentioned in more than one references listed above to ensure their broad acceptance; 2) they are applicable to the general remediation community rather than any one specific country context; and 3) they can be used to gauge behavior rather than simply technological measures. Moreover, a pilot study was used to ensure that these sustainable behavior measures can be interpreted by remediation practitioners. The adoption of each sustainable behavior was measured in the questionnaire by asking: "how effective is your team in adopting the following 'sustainability' considerations in developing remediation strategies?" The responses were given on a 5-point scale. The anchors were "not at all" (1) and "very effective" (5). In addition, the promoting forces and barriers, identified from the review of existing literature, were measured by two questions. The promoting forces were based on the question: "How important are the factors listed below in motivating your team to adopt sustainable practices in remediation?" The responses were given on a 5-point scale. The anchors were "not at all" (1) and "very effective" (5). The barriers were based on the question: "Have the following barriers impeded your 
team in adopting sustainable practices in remediation?" The anchors were "not at all" (1) and "very significantly" (5).

The survey was initially conducted in 2012. In 2014, the questionnaire was revised and the survey was conducted again. The revised questionnaire included several new questions to gauge the respondent's perception of sustainable remediation adoption in their home country, in addition to the questions pertaining to their own behavior. The revised questionnaire also included questions to measure how often and what kind of tools the respondents used to conduct sustainability assessment in the respondents practice. Due to paper length limit, these additional survey questions are only briefly described in the results section.

\subsection{Survey Procedures}

The survey was conducted according to general questionnaire survey guidance (Brace, 2004; Dillman, 2007; Saris and Gallhofer, 2007). A pilot questionnaire test was conducted. In the pilot study, the draft questionnaire survey was sent to seven remediation professionals for testing. The pilot test participant was asked to complete the survey, to provide comments on whether the questionnaire survey was readable, whether the questions make sense, and whether they have any comments for improving the design of the questionnaire survey. Moreover, the participants were asked to gauge the time required to complete the survey. Upon receipt of the pilot test results, the questionnaire survey was revised to incorporate these comments. A finalized survey questionnaire was setup online. A link to the online survey was then sent to potential participants by emails. The invitation letter included a cover letter explaining the objective of the survey, and assured that the confidentiality of respondent would be guaranteed. The survey was directly sent to 1,480 potential participants through individual emails. In addition, the survey was promoted on newsletters sent by professional organizations and online remediation forums, and additional participants were solicited in a snow-ball fashion. 
The first round of survey was conducted in July-October 2012. The survey questionnaire was setup online and emailed to potential survey participants. A total of 223 effective responses were received from survey participants in 16 countries. The second round of survey were conducted in November 2014. A total of 150 effective responses was received from survey participants in 18 countries. To encourage participation, the participants in both rounds of survey were offered a future summary report of the aggregated results to those who explicitly expressed interest. During the first round of survey, several reminder emails were sent to all participants who had not responded, or who started, but not finished responding. Reminder emails were not sent during the second round of survey.

The survey target population included all stakeholders involved in environmental remediation decision making and practices. The survey participants were mainly owners of contaminated sites, regulators, and environmental consultants, but also included contractors, technology vendors, environmental groups, etc. It was estimated that the first round of survey had a response rate of $9.5 \%$, and the second round of survey had a response rate of $7.6 \%$. Based on analysis of variance (ANOVA) tests, these procedures did not lead to biased results, with the exception of the offering of a survey summary report as an incentive, which may have led to a bias in favor of respondent ratings as for the adoption of sustainable practices.

\subsection{Data Analysis}

Due to the limit of survey data, the present study chose not to use parametric inference to derive the average and standard error of the responses. Instead, a bootstrapping algorithm was used to derive the average and standard errors. The bootstrapping algorithm randomly draws samples from the original data repeatedly to calculate the target statistics, such as sample mean, and then to derive test statistics and related confidence intervals. The bootstrapping method assumes that the variability in a statistical property of the dataset, for example, the mean difference of two groups of sample, will be mimicked by the variability in the same property of a 
large number of resampled datasets. The comparison between every two measurement items was conducted using a bootstrapping method based independent-sample t-test. The randomization tests were performed using SPSS software (IBM, 2011). In each bootstrap test, 1000 bootstrap replicates are used, which is considered sufficient (Pattengale et al., 2010). The present study chose the bootstrapping procedure because with the computing power of modern computers, the bootstrapping procedure is simple to implement, and the bootstrapping method provides more accurate estimates than conventional methods that are based on standard intervals obtained using sample variance and assumption of normality (DiCiccio and Efron, 1996). Moreover, standard error estimators need to be adjusted to address "design effects" in questionnaire survey, and it is more convenient to use bootstrapping methods (Thompson et al., 2006). The questionnaire survey was based on a Likert scale of 1 to 5 , which means that the data were not strictly normally distributed and not continuous. The bootstrapping procedure has been widely used in analyzing questionnaire survey data (Gillet et al., 2013), as well as in environmental science studies (Reichstein et al., 2003). The present study did not use repeated measure approach because the responses from the 2012 and 2014 surveys were not paired.

\subsection{Limitations of the Method}

This study was limited in that the survey was not conducted in a random manner. Random sampling was not feasible because there was no central database of remediation practitioners. Therefore, the survey results may not necessarily represent the true mean of the general population being surveyed, i.e. the survey may be biased toward the group of remediation practitioners who have more awareness of sustainable remediation. The survey response rate was also relatively low compared to those reported in social studies. However, our experience indicated a survey of professionals is generally more difficult than survey of the general public, likely due to the fact that most professionals are not willing to spend time on "unproductive" tasks while at work. The response rate reported in this study appears to be reasonably high 
compared to other survey studies among professionals. For the spatial analysis, this study had a relatively small sample size for most countries except for a few major countries. Countries like Australia, Italy, Netherland, and Canada are all active in promoting sustainable remediation; however, responses from these countries are low due to lack of contacts. In order to address this limitation, the developed countries other than the US and the UK are grouped together to render aggregated results. For the temporal analysis, this study only provided two temporal data points (i.e. year 2012 and year 2014). Therefore, this study is considered exploratory, and the results may only be interpreted with the limitations bearing in mind. However, this study may also be used as a baseline for future studies.

\section{RESULTS}

\subsection{Respondents' profile}

\subsubsection{Country origin}

The two questionnaire surveys received responses from 22 countries (see Table 1). The majority of the responses were from the US (51\%) and UK (23\%). The response rates from the other countries were relatively low, so they were aggregated into three groups: Asian countries including China, India, Japan, and South Korea (11\%), other developed countries including 10 other countries in Europe (i.e. France, Germany, Israel, Ireland, Italy, Netherland, Sweden, Belgium, Czech Republic, Denmark) plus Canada and Australia (10\%), and other four developing countries in Latin America and Africa (i.e. Brazil, Mexico, Nigeria, South Africa) (5\%). 
Table 1 Respondents' Composition

\begin{tabular}{|c|c|c|c|c|c|}
\hline Country/Reg ion & $\mathrm{N}$ & $\%$ & Stakeholder & $\mathrm{N}$ & $\%$ \\
\hline USA & 191 & 51 & Prim ary consultant & 177 & $47.5 \%$ \\
\hline $\mathrm{UK}$ & 84 & 23 & Regulator & 44 & $11.8 \%$ \\
\hline A sia (4 Countries) & 42 & 11 & Specialty consultant & 37 & $9.9 \%$ \\
\hline \multicolumn{6}{|l|}{0 ther 12 D eveloped } \\
\hline Countries & 39 & 10 & A cadem ic & 33 & $8.8 \%$ \\
\hline \multicolumn{6}{|l|}{0 ther $4 \mathrm{D}$ eve lop ing } \\
\hline \multirow[t]{12}{*}{ Countries } & 17 & 5 & Site ow ner & 21 & $5.6 \%$ \\
\hline & & & Tech. vendor & 20 & $5.4 \%$ \\
\hline & & & Prim ary contractor & 17 & $4.6 \%$ \\
\hline & & & Laboratory & 6 & $1.6 \%$ \\
\hline & & & Environ. group & 6 & $1.6 \%$ \\
\hline & & & Reag ent supp lier & 6 & $1.6 \%$ \\
\hline & & & Equip. vendor & 3 & $0.8 \%$ \\
\hline & & & D riller & 3 & $0.8 \%$ \\
\hline & & & Site user & 0 & $0.0 \%$ \\
\hline & & & Site neighbor & 0 & $0.0 \%$ \\
\hline & & & Land developer & 0 & $0.0 \%$ \\
\hline & 373 & $100 \%$ & To tal & 373 & $100 \%$ \\
\hline
\end{tabular}

Note: $\mathrm{N}$ represents the number of respondents from each country/region or from each type of stakeholder; \% represents the percentage of total respondents from that country/region, or total respondents from that type of stakeholder

\subsubsection{Stakeholder representation}

The present study divided all stakeholders pertaining to remediation decision making into 15 categories (Hou, 2014; Rizzo, 2015). As shown in Table 1, primary consultant (47.5\%) accounted for the largest portion of respondents, followed by regulator (11.8\%), specialty consultant (9.9\%), academic (8.8\%), site owner (5.6\%), key technology vendor (5.4\%), and primary contractor (4.6\%). The remaining eight type of stakeholders accounted for only $6.4 \%$ respondents in total, and three types of them (site user, site neighbor, and land developer) were unrepresented. 


\subsection{Adoption of Sustainable Remediation Practices}

\subsubsection{Overall Awareness and Adoption}

The overall awareness and adoption of sustainable remediation were measured by five questions. The personal view of each individual remediation practitioner was measured by the question "in your personal view, how important should 'sustainability' considerations be in remediation decision making processes", on a Likert scale of 1 to 5. As Figure 2 shows, respondents from the US, the UK, and other developed countries gave similar importance to sustainability. It is interesting to note that respondents from Asia gave even higher importance to sustainability (4.50); while respondents from other developing countries gave much lower importance to sustainability (3.24).

The awareness and adoption of sustainable remediation on an organization level was measured by the question "use a scale of 1 to 5 to describe to what extent your organization's 'sustainability' policies are applicable to remediation practices that you are involved in", on a Likert scale of 1 to 5 . As Figure 2 shows, the US and the UK had the highest rating (3.39 and 3.4, respectively), followed by Asia and other developed countries (3.09 and 2.91 respectively), and other developing countries (2.24). The differences between US, UK, Asia and other developed countries were within the error ranges, but other developing countries appeared to have statistically significantly lower rating on this measure.

The awareness of sustainable remediation on a country level was measured by the question "use a scale of 1 to 5 to describe to what extent remediation practitioners in this country are aware of 'sustainable remediation'", on a Likert scale of 1 to 5 . Figure 2 shows that the US and the UK had the highest rating (3.88 and 4.00 respectively), and that Asia and other developing countries have much lower rating (2.50 and 2.60 respectively). It appears that regarding the awareness of sustainable remediation, the US and the UK were at similar levels, while Asia and other developing countries were 
significantly lower.

The promoting force of sustainable remediation was measured by the question "use a scale of 1 to 5 to describe the strength of forces promoting "sustainable remediation" in this country". The US, UK, other developed countries, and Asia countries had similar ratings $(2.91,2.95,2.9$, and 2.7 respectively). Other developing countries had the lowest rating of 1.87 , which was substantially lower than those in the US, the UK, and Asia.

The overall adoption of sustainable remediation was measured by the question "use a scale of 1 to 5 to describe how effective remediation practitioners in this country are adopting 'sustainable remediation'”. Figure 2 shows that there were much higher adoption rate of sustainable remediation in the US (2.78) and the UK (2.88) than those in other developing countries (1.63).

\subsubsection{Adoption of Individual Sustainable Practices}

As described in Section 2.1, the adoption of 27 individual sustainable practices in remediation was measured in both the 2012 and the 2014 survey. To align with the scope of this special issue, fifteen sustainable practices were selected to represent "sustainable regeneration and land use", "sustainable soil management", and "green remediation practice", corresponding to the sustainable practices advocated by the UK, the Netherland, and the US, respectively. The average rating and standard error of these sustainable practices are shown in Table 2.

Table 2 Adoption of sustainable remediation practices in various countries/regions

\begin{tabular}{lccccc}
\hline Country/Region & US & UK & Asia & Developed Developing \\
\hline \multicolumn{4}{c}{ Sustainable regeneration and land use } \\
& & & & \\
Maximize area for redevelopment & $3.74 \pm 0.08$ & $4.06 \pm 0.13$ & $3.27 \pm 0.22$ & $3.44 \pm 0.19$ & $4.06 \pm 0.19$ \\
Reduce local community risk & & & & & \\
& $4.3 \pm 0.07$ & $4.24 \pm 0.11$ & $3.82 \pm 0.17$ & $3.8 \pm 0.23$ & $4.19 \pm 0.32$ \\
\hline
\end{tabular}




\begin{tabular}{llllll}
\hline Enhance local employment & $2.88 \pm 0.09$ & $2.94 \pm 0.17$ & $2.15 \pm 0.16$ & $2.52 \pm 0.17$ & $2.56 \pm 0.36$ \\
Use fast track remedial alternative & & & & & \\
& $3.46 \pm 0.08$ & $3.52 \pm 0.13$ & $3.82 \pm 0.17$ & $3.12 \pm 0.18$ & $3.44 \pm 0.27$ \\
Reduce site workers risk & & & & & $4.69 \pm 0.15$ \\
Bring prosperity to disadvantaged community & $2.3 \pm 0.09$ & $2.43 \pm 0.16$ & $2.33 \pm 0.2$ & $1.92 \pm 0.16$ & $1.56 \pm 0.23$
\end{tabular}

Sustainable soil management

\begin{tabular}{|c|c|c|c|c|c|}
\hline Use MNA rather than active remediation & $3.79 \pm 0.08$ & $3.48 \pm 0.16$ & $2.76 \pm 0.2$ & $3.28 \pm 0.23$ & $2.19 \pm 0.33$ \\
\hline Enhance reuse and recycling & $3.34 \pm 0.08$ & $3.9 \pm 0.11$ & $3.27 \pm 0.18$ & $3.04 \pm 0.22$ & $3.25 \pm 0.25$ \\
\hline Minimize long-term monitoring & $3.65 \pm 0.07$ & $3.83 \pm 0.11$ & $3.36 \pm 0.19$ & $3.04 \pm 0.24$ & $3 \pm 0.31$ \\
\hline Minimize water consumption & $3.23 \pm 0.08$ & $3.27 \pm 0.14$ & $2.94 \pm 0.16$ & $3.04 \pm 0.25$ & $3.44 \pm 0.3$ \\
\hline \multicolumn{6}{|c|}{ Green remediation - minimizing environmental impacts } \\
\hline Minimize noise, dust, odor, traffic & $3.83 \pm 0.07$ & $4.17 \pm 0.1$ & $3.76 \pm 0.18$ & $3.64 \pm 0.2$ & $3.44 \pm 0.25$ \\
\hline Minimize GHG emission, fossil fuel depletion & $2.95 \pm 0.08$ & $3.05 \pm 0.15$ & $2.64 \pm 0.19$ & $2.64 \pm 0.2$ & $2.56 \pm 0.26$ \\
\hline Use in-situ rather than ex-situ remedy & $4.28 \pm 0.07$ & $3.51 \pm 0.14$ & $3.3 \pm 0.18$ & $3.96 \pm 0.19$ & $4.25 \pm 0.21$ \\
\hline Minimize energy use & $3.21 \pm 0.07$ & $3.17 \pm 0.13$ & $2.85 \pm 0.2$ & $2.88 \pm 0.17$ & $3.31 \pm 0.26$ \\
\hline Minimize contaminants left behind & $3.91 \pm 0.08$ & $3.94 \pm 0.12$ & $4.18 \pm 0.17$ & $3.64 \pm 0.24$ & $3.94 \pm 0.23$ \\
\hline Minimize waste generation & $3.77 \pm 0.07$ & $4.11 \pm 0.13$ & $3.76 \pm 0.18$ & $3.36 \pm 0.23$ & $3.69 \pm 0.17$ \\
\hline
\end{tabular}

Note: the " \pm " sign shows the error range.

In the category of "sustainable regeneration and land use", the US and the UK had similar ratings for most types of practices; Asia had relatively low rating for nearly all practices, but had relatively high rating for "use fast track remedial alternative" (3.82); other developing countries had relatively low rating for "bring prosperity to disadvantaged community" and "enhance local employment". When comparing different individual practices, across all regions, the practices pertaining to risk 
mitigation, i.e. "reduce local community risk" and "reduce site workers risk" had the highest adoption rate; while the practices pertaining to socioeconomic sustainability, i.e. "enhance local employment" and "bring prosperity to disadvantaged community" had the lowest adoption rate.

In the category of "sustainable soil management", the US had the highest rating in "use MNA rather than active remediation" (3.79), the UK had the highest rating in "enhance reuse and recycle" (3.90), Asia had the highest rating in "minimize long term monitoring" (3.36), and other developing countries had the highest rating in "minimize water consumption" (3.44). When comparing different individual practices, they have similar adoption rates in each region, with the exception of other developing countries, where "use MNA rather than active remediation" had a dramatically low rating (2.19).

In the category of "green remediation", the US and the UK had relatively high rating on nearly all categories, Asia had relatively high rating on "minimize contaminants left behind" (4.18), and other developing countries had relatively high rating on "use in-situ rather than ex-situ remedy" (4.25). When comparing different individual practices, "minimize local secondary impact like noise, dust, odor", "use in-situ rather than ex-situ remedy", and "minimize contaminants left behind" appeared to have relatively high adoption rates in most regions. In comparison, "minimize national to global secondary impact like greenhouse gas emission" had relatively low adoption rate in nearly all regions.

\subsection{Sustainability Assessment}

The 2014 survey measured the usage of four sustainability assessment methods: qualitative sustainability assessment, multi-criteria analysis (MCA), life cycle assessment (LCA), and economic cost benefit analysis (CBA), within the projects where remediation practitioners had conducted sustainable evaluation. The 
respondents were asked the question "among all remediation projects on which you have conducted sustainability evaluation, please indicate the percentage of usage of each of the following methods". As Figure 3 shows, CBA was the most widely used method in the US (38\%), Asia (37\%), other developed countries (41\%), and other developing countries (62\%). While CBA was also used in the UK at a high ratio (29\%), qualitative sustainability assessment was the most widely used method in the UK (48\%). MCA was used in all regions at a similar ratio, ranging from $14 \%$ to $22 \%$, all within each other's error range. LCA was mostly used in the US (20\%) and Asia (21\%), but it was least used in the UK (7\%) and other developing countries (7\%). It should be noted that these percentages only measure the relatively popularity of the various sustainability assessment methods.

\subsection{Temporal Variation}

\subsubsection{Sustainable Remediation Practices}

Figure 4 shows the change in the adoption of sustainable practices in the US from 2012 to 2014. Only data from the US are used for the assessment of temporal variation because this is the only country where sufficient responses were received in both 2012 and 2014. Only 8 typical sustainable practices are shown to provide a concise view. Both Figure 4 and data not shown indicate that the adoption rate of most sustainable practices did not change significantly from 2012 and 2014. For practices such as "minimize energy use", "use MNA rather than active remediation", "use sustainable energy", "enhance reuse and recycling", the adoption rate essentially remained the same from 2012 to 2014. For "minimizing local scale secondary impact", the adoption rate changed from 4.01 to 3.56 , indicating a statistically significant decrease $(p=0.001)$. For "minimizing national to global scale secondary impact", the adoption rate changed from 3.14 to 2.58 , also representing a statistically significant decrease $(p=0.001)$. As for "bring prosperity to disadvantaged community", there was also a statistically significant decrease $(p=0.014)$, dropping from 2.42 to 2.00 . 


\subsubsection{Sustainable Remediation Promoting Forces}

The survey asked respondents about the effect of 10 promoting forces of sustainable remediation. The five top promoting forces were "improve competitiveness", "align with organization's high level policy", "improve relations with local community", "enhance public image", and "future regulatory compliance". As Figure 5 shows, in 2012, "align with organization's high level policy" was the most important promoting force (3.97). Its rating dropped to 3.63 in the 2014 survey, but remained as the most important promoting force. The decrease in rating was statistically significant at an alpha level of $0.5(p=0.023)$. The secondly and thirdly important promoting forces in 2012 were "enhance public image" (3.83) and "improve competitiveness", and in 2014 they dropped to 3.63 and 3.43 , respectively. Both decreases were not statically significant at an alpha level of 0.05 . The fourthly and fifthly important promoting forces in 2012 were "future regulatory compliance" (3.75) and "improve relations with local community" (3.72), and in 2014 they both dropped to 3.61. Both decreases were not statically significant at an alpha level of 0.05 .

\subsubsection{Sustainable Remediation Barriers}

The survey asked respondents about the effect of 9 barriers of sustainable remediation. The five top barriers were "lack of client demand", "lack of consistent standard", "lack of expertise/training/resource", "cost considerations", and "no regulatory mandate". It was found that "no regulatory command" became a stronger barrier from 2012 to 2014 , with its rating increased from 3.30 to 3.74 ( $p=0.074)$. On the other hand, "lack of expertise/training/resource" is no longer as strong a barrier in 2014 as in 2014 , with its rating decreased from 2.88 to $2.61(p=0.080)$. Among the other three barriers, two of them increased slightly and one of them remained the same rating. 


\section{DISCUSSION}

Sustainable remediation is not only a technology issue, but more importantly, a behavior issue. The decision made by practitioners in every step of the remediation process ultimately determines the sustainability of remediation projects. Decision-making by remediation professionals in different geographic areas and time points may differ due to social, economic, cultural, and regulatory differences. Based on two questionnaire surveys conducted in 2012 and 2014, this study found that the awareness, adoption, and practice of sustainable remediation display statistically significant regional divergence and temporal variation.

Overall, among these five country/region groups: US, UK, Asia, other developed countries, and other developing countries, the first two countries tend to have higher awareness and adoption rate of sustainable remediation, while the other developing countries tend to have lower awareness and adoption rate. For all countries/regions, the respondents of the survey have higher self-awareness of the sustainable remediation than the national average awareness. While this may reflect the fact that the survey disproportionally drawn respondents from those remediation practitioners who are more interested in sustainable remediation; it may also be partially explained by a common perception bias due to unrealistic optimism and illusory superiority, i.e. people tend to view themselves better than how they are viewed by the others (Hoorens, 1995). On the other hand, this gap between personal awareness and country awareness is relatively small in the US and the UK, and it became larger in other developing countries, and became extremely large in Asia. There is no easy explanation for the largest discrepancy in Asia. In addition to biased sample representation, it is also likely that, due to a lack of institutional driving forces (e.g. advocacy by organizations) in Asia, the respondents in this region had limited knowledge about the others awareness of sustainable remediation.

Two distinct theories have been proposed to explain people's adaptive behavior in the 
face of environmental changes. An often cited theory is the so-called information-deficit model, which states that the lack of information is the main obstacle to effective engagement and enhanced awareness can improve adoption of sustainable behavior (Bulkeley, 2000). Another theory, the three-states model, suggests that engagement in adaptation involves cognitive (what one knows), affective (how one makes sense of this knowledge), and behavioral (what action one takes) states at both individual and social scales (Lorenzoni et al., 2007). Results from the present study seem to support the three-states model. In both the US and the UK, the survey respondents perceived that sustainability should be an important consideration in remediation decision making. Based on their response, remediation practitioners in these two regions generally have high awareness of sustainable remediation. However, the promoting forces of sustainable remediation are much lower, correspondingly the adoption of sustainable remediation in these two regions were similarly lower. In addition, based on survey responses, it appears that many remediation practitioners have limited knowledge of what sustainable remediation is really about. Therefore, in the sustainable remediation field, the cognitive state maybe high, but the affective and behavioral states may be lower. This suggests that, in order to promote sustainable remediation, it is imperative to enhance the affective and behavioral states of remediation practitioners. This is consistent with other studies which have suggested that campaigns focusing on increasing awareness may achieve little attitudinal or behavioral change (O'Neill and Hulme, 2009).

This study suggests that practices pertaining to risk control, e.g. "reduce local community risk" and "reduce site workers risk", are still of paramount importance among remediation practitioners. This statement remains true in all regions surveyed in this study. In contrast, socioeconomic values such as "enhance local employment" and "bring prosperity to disadvantaged community" are not well adopted by professionals. This finding is consistent with existing literature which suggest that current remediation practices are short of social and economic sustainability considerations (ITRC, 2011). Among the various sustainable practices, greenhouse 
gas emission reduction is probably the most extensively mentioned subject. It is also a key environmental stressor of various LCA studies published in literature. However, this study showed that the adoption of practices to minimize greenhouse gas emission was very low, suggesting a gap between awareness and practice.

A key component of sustainable remediation is sustainability assessment, which can be used to inform the selection and optimization of remedial actions (Ellis and Hadley, 2009). A variety of tools have been used in evaluating the sustainability of remedial alternatives: qualitative sustainability assessment (Bardos, 2012), MCA (Sparrevik et al., 2012), LCA (Hou et al., 2014b), CBA (Harclerode et al., 2015; Postle, 1999). The present survey indicates that CBA is still the most popular sustainability assessment method. However, to the authors' knowledge, the cost benefit analyses conducted by remediation practitioners are not strictly speaking CBA, which usually attempts to quantify the monetary value of intangible costs and benefits. It is likely that the survey's respondents consider the traditional cost analysis as CBA. On the other hand, researchers have indicated that $\mathrm{CBA}$ has difficulties in monetarize the value of certain sustainable remediation options such as soft reuse of brownfield sites (Bardos et al., 2015). The present survey indicated that qualitative assessment was more widely used in the UK than in the US, while LCA was more widely used in the US than in the UK. This is consistent with the authors observation during remediation practice. This discrepancy maybe partly due to the fact that various US governments have developed LCA tools for conducting streamlined LCA for remediation projects. These tools include USEPA's footprint analysis spreadsheet (USEPA, 2012), the Navy's SiteWise tool (NAVFAC, 2013), and the Air Force's Sustainable Remediation Tool (SRT) (AFCEE, 2010).

The core messages of the ongoing sustainable remediation movement include: 1) encouraging life cycle thinking to reduce secondary impacts from remediation, i.e. to go beyond geographical boundaries and time scales to provide a holistic evaluation of cost and benefit (Morais and Delerue-Matos, 2010); and 2) incorporating social and 
economic externalities in decision making (Ellis and Hadley, 2009). While Figure 1 shows that literature regarding sustainable remediation has an overall increasing trend from 2007 to 2014, it seems that the sustainable remediation community was the most active in 2011 and 2012. For instance, new national sustainable remediation forums were formed in Brazil and Canada in 2011, and in Taiwan and Italy in 2012. Some important guidance documents have been published after 2012, most notably the ASTM greener cleanup guidance published in 2013 and a draft sustainable remediation ISO standard published in 2015 (ASTM, 2013; ISO, 2015). However, it is likely that such institutional promoting forces were not as strong in 2014 in comparison with 2012. In the remediation field, two years is a short time period, as many remediation projects last for much longer than two years. Therefore, the actual decision made regarding any specific project is not likely to have changed significantly over a two-year period. However, the perceptive state of the survey respondents was very likely to have been affected by what they hear and what they read near the time of survey. Their actual behavior on one project conducted in 2012 and another project conducted in 2014 may also be different due to their different cognitive and affective states in these two time periods. When comparing survey results between 2012 and 2014, it is interesting to note that three core sustainable practices, "minimize local scale secondary impact", "minimizing national to global scale secondary impact", and "bring prosperity to disadvantaged community", all had significant decrease in their adoption rates (Section 3.4.1). On the other hand, it is noted that some barrier, e.g. "no regulatory mandate" became stronger while some other barrier, e.g. "lack of expertise/training/resources" was weakened in 2014. These results present mixed message, but overall suggesting that in order to enhance sustainable remediation, more sustained efforts are required to build up more promoting forces and overcoming barriers.

\section{CONCLUSION}

The present study used two rounds of questionnaire surveys, conducted in 2012 and 
2014, to gauge the awareness and practice of sustainable remediation by professionals in different regions of the world. The survey results indicate that the US and the UK similarly had the highest level of awareness of sustainable remediation. These two countries also had the highest rate of adoption of sustainable practices in the remediation field. In comparison, Asia had lower and other developing countries had much lower awareness levels and adoption rates. This study also suggests that remediation professionals in developed countries in Europe and North America maybe at a high cognitive state, but relatively low affective and behavioral state, thus resulting in a lower adoption rate than what the awareness level would otherwise dictate. The adoption of practices to minimize greenhouse gas emission was particularly low, even though GHG mitigation has been a hot subject in sustainable remediation literature. This study also indicates that the adoption rate of a few sustainable remediation measures have decreased significantly, probably due to a slowdown in some promoting forces and increasing in some barrier forces. This study suggests that, in order to promote the practice of sustainable remediation, it is imperative to go beyond awareness campaign. Policy makers must develop instrument to enhance the understanding by practitioners of what sustainable remediation is really about, and to enhance the self-interest and public interest of sustainable remediation. Moreover, such effort must be continuous rather than being on a pulse mode.

\section{Acknowledgements}

The primary author's work is supported by the Thousand Youth Talent Program of China.

\section{References:}

AFCEE, 2010. Sustainable Remediation Tool User Guide, AFCEE. Air Force Center for Engineering and the Environment, Lackland, Texas. 
Bardos, P., 2012. Conceptual Site or Project Models for Sustainability Assessment, in: The 2nd International Conference on Sustainable Remediation. Vienna, Austria.

Bardos, P., Bone, B., Boyle, R., Ellis, D., Evans, F., Harries, N.D., Smith, J.W.N., 2011. Applying sustainable development principles to contaminated land management using the SuRF-UK framework. Remediat. J. 21, 77-100.

Bardos, R.P., Jones, S., Stephenson, I., Menger, P., Beumer, V., Neonato, F., Maring, L., Ferber, U., Track, T., Wendler, K., 2015. Optimising value from the soft re-use of brownfield sites. Sci. Total Environ.

Brace, I., 2004. Questionnaire design: how to plan, structure, and write survey material for effective market research. Kogan Page Ltd, London \& Sterling, VA.

Bulkeley, H., 2000. Common knowledge? Public understanding of climate change in Newcastle, Australia. Public Underst. Sci. 9, 313-334.

DiCiccio, T.J., Efron, B., 1996. Bootstrap confidence intervals. Statistical science, 189-212.

Dillman, D.A., 2007. Mail and internet surveys: The tailored design method. John Wiley \& Sons.

EA, 2009. Reporting the evidence: Dealing with contaminated land in England and Wales - A review of progress from 2000-2007 with Part 2A of the Environmental Protection Act. Environment Agency, Bristol, UK.

Ellis, D.E., Hadley, P.W., 2009. Sustainable remediation white paper-Integrating sustainable principles, practices, and metrics into remediation projects. Remediat. J. 19, 5-114.

EURODEMO., 2007. Framework for Sustainable Land Remediation and Management. European Co-ordination Action for Demonstration of Effiient Soil and Groundwater 
Remediation.

Gillet, N., Fouquereau, E., Bonnaud-Antignac, A., Mokounkolo, R., Colombat, P., 2013. The mediating role of organizational justice in the relationship between transformational leadership and nurses' quality of work life: A cross-sectional questionnaire survey. International journal of nursing studies 50, 1359-1367.

Harclerode, M.A., Lal, P., Miller, M.E., 2015. Quantifying global impacts to society from the consumption of natural resources during environmental remediation activities. J. Ind. Ecol.

Hoorens, V., 1995. Self-favoring biases, self-presentation, and the self-other asymmetry in social comparison. J. Pers. 63, 793-817.

Hou, D., Al-Tabbaa, A., 2014. Sustainability: A new imperative in contaminated land remediation. Environ. Sci. Policy 39, 25-34.

Hou, D., Al-Tabbaa, A., Guthrie, P., 2014a. The adoption of sustainable remediation behaviour in the US and UK: A cross country comparison and determinant analysis. Sci. Total Environ. 490, 905-913.

Hou, D., Al-Tabbaa, A., Guthrie, P., Hellings, J., 2014b. Using a Hybrid LCA Method to Evaluate the Sustainability of Sediment Remediation at the London Olympic Park. J. Clean. Prod. 83, 87-95.

Hou, D., Al-Tabbaa, A., Luo, J., 2014c. Assessing Effects of Site Characteristics on Remediation Secondary Life Cycle Impact with a Generalized Framework. J. Environ. Plan. Manag. 57. doi:10.1080/09640568.2013.863754

IBM, 2011. IBM SPSS Bootstrapping 20.

ITRC, 2011. Green and Sustainable Remediation: State of the Science and Practice, ITRC. Interstate Technology \& Regulatory Council, Washington, DC, USA. 
Lorenzoni, I., Nicholson-Cole, S., Whitmarsh, L., 2007. Barriers perceived to engaging with climate change among the UK public and their policy implications. Glob. Environ. Chang. $17,445-459$.

Madejón, P., Barba-Brioso, C., Lepp, N.W., Fernández-Caliani, J.C., 2011. Traditional agricultural practices enable sustainable remediation of highly polluted soils in Southern Spain for cultivation of food crops. J. Environ. Manage.

Maurer, O., 2009. NICOLE's Shared Vision on Sustainable Remediation, in: Green Remediation Conference. Copenhagen, Denmark.

MEP, 2014. National Soil Contamination Survey Report. Ministry of Environmental Protection, Beijing, China.

Morais, S.A., Delerue-Matos, C., 2010. A perspective on LCA application in site remediation services: critical review of challenges. J. Hazard. Mater. 175, 12-22. doi:10.1016/j.jhazmat.2009.10.041

NAVFAC, 2013. SiteWise Version 3 User Guide.

O’Neill, S.J., Hulme, M., 2009. An iconic approach for representing climate change. Glob. Environ. Chang. 19, 402-410.

Pattengale, N.D., Alipour, M., Bininda-Emonds, O.R.P., Moret, B.M.E., Stamatakis, A., 2010. How many bootstrap replicates are necessary? J. Comput. Biol. 17, 337-354.

Postle, E., 1999. Cost-Benefit Analysis for Remediation of Land Contamination. R\&D Technical Report P316, Postle, EA. Environment Agency, London, UK.

Prior, J., 2016. The norms, rules and motivational values driving sustainable remediation of contaminated environments: A study of implementation. Sci. Total Environ. 544, 824- 
836.

Reichstein, M., Rey, A., Freibauer, A., Tenhunen, J., Valentini, R., Banza, J., Casals, P., Cheng, Y., Grünzweig, J.M., Irvine, J., 2003. Modeling temporal and large - scale spatial variability of soil respiration from soil water availability, temperature and vegetation productivity indices. Global biogeochemical cycles 17.

Saris, W.E., Gallhofer, I.N., 2007. Design, evaluation, and analysis of questionnaires for survey research. Wiley-Interscience.

Sparrevik, M., Barton, D.N., Bates, M.E., Linkov, I., 2012. Use of Stochastic Multi-Criteria Decision Analysis to Support Sustainable Management of Contaminated Sediments.

Environ. Sci. Technol. 46, 1326-1334. doi:10.1021/es202225x

Surf-UK, 2010. A Framework for Assessing the Sustainability of Soil and Groundwater Remediation, CLAIRE. Contaminated Land: Applications in Real Environments, London, UK.

Surf-UK, 2009. A Review of Published Sustainability Indicator Sets: How applicable are they to contaminated land remediation indicator-set development? Contaminated Land: Applications in Real Environments (CL:AIRE), London, UK.

Thompson, M.E., Fong, G.T., Hammond, D., Boudreau, C., Driezen, P., Hyland, A., Borland, R., Cummings, K.M., Hastings, G.B., Siahpush, M., 2006. Methods of the International Tobacco Control (ITC) four country survey. Tobacco Control 15, iii12-iii18.

USACE, 2010. Decision Framework for Incorporation of Green and Sustainable Practices into

Environmental Remediation Projects, USACE. United States Army Corps of Engineers,

Washington, DC.

USEPA, 2013. NPL Site Totals by Status and Milestone [WWW Document]. URL

http://www.epa.gov/superfund/sites/query/queryhtm/npltotal.htm

USEPA, 2012. SEFA: Spreadsheets for Environmental Footprint Analysis. 
USEPA, 2010. OSWER Cross-Program Revitalization Measures.

USEPA, 2008. Green Remediation: Incorporating Sustainable Environmental Practices into Remediation of Contaminated Sites. EPA 542-R-08-002., USEPA. United States Environmental Protection Agency, Washington, DC.

USEPA, 2004. Cleaning Up the Nation's Waste Sites: Markets and Technology Trends, 2004 Edition. United States Environmental Protection Agency, Washington, DC.

Witters, N., Mendelsohn, R., Van Passel, S., Van Slycken, S., Weyens, N., Schreurs, E., Meers, E., Tack, F., Vanheusden, B., Vangronsveld, J., 2012. Phytoremediation, a sustainable remediation technology? II: Economic assessment of CO 2 abatement through the use of phytoremediation crops for renewable energy production. Biomass and bioenergy $39,470-477$. 
List of Figures:

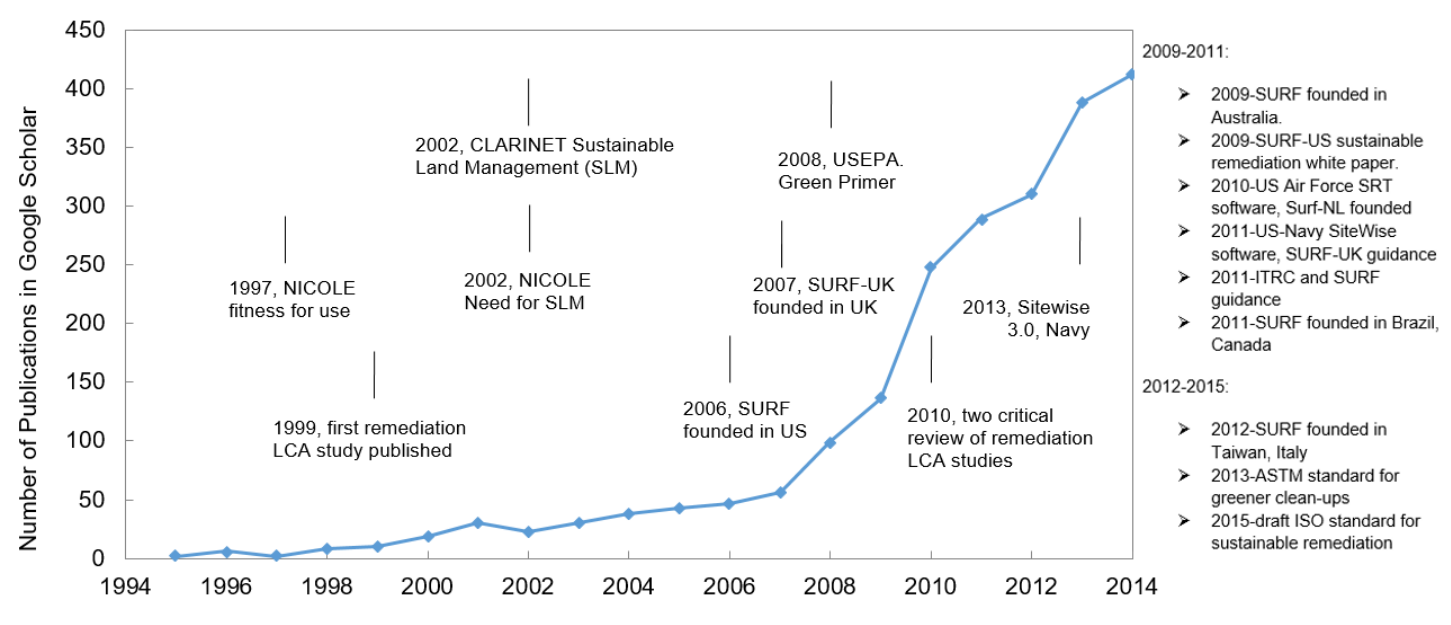

Figure 1. Exponential growth in sustainable remediation publication and historical events.

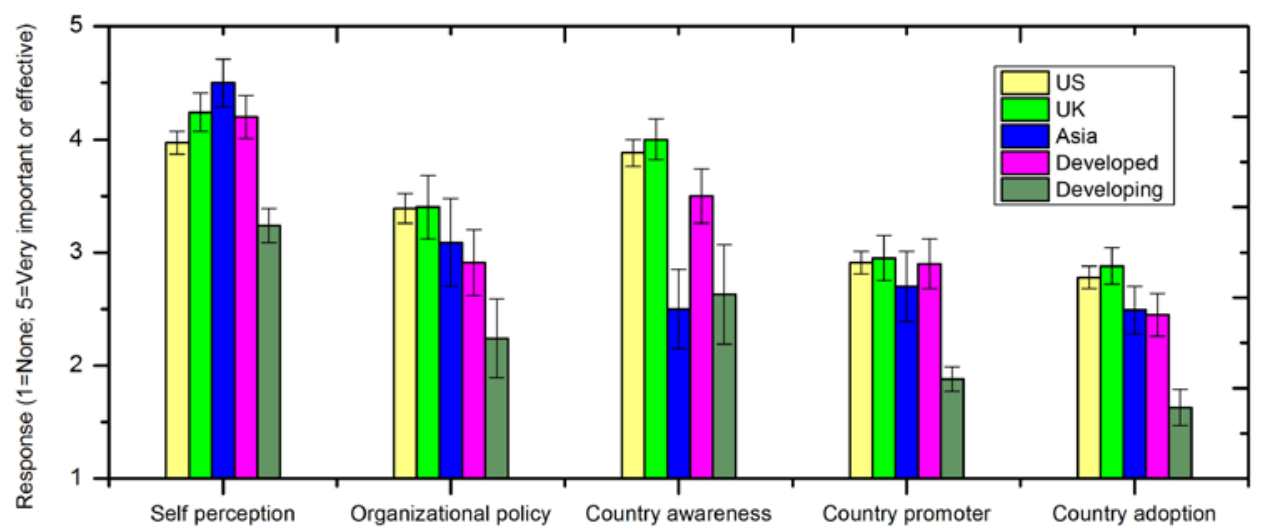

Figure 2. Overall view of sustainable remediation by respondents from different countries/regions (self-perception is measured by "in your personal view, how important should 'sustainability' considerations be in remediation decision making processes"; organizational policy is measured by "use a scale of 1 to 5 to describe to what extent your organization's 'sustainability' policies are applicable to remediation practices that you are involved in" ; country awareness is measured by "use a scale of 1 to 5 to describe to what extent remediation practitioners in this country are aware of 'sustainable remediation'"; country promoter is measured by "use a scale of 1 to 5 to describe the strength of forces promoting "sustainable remediation" in this country"; country adoption is measured by "use a scale of 1 to 5 to describe how effective remediation practitioners in this country are adopting 'sustainable remediation'”). 


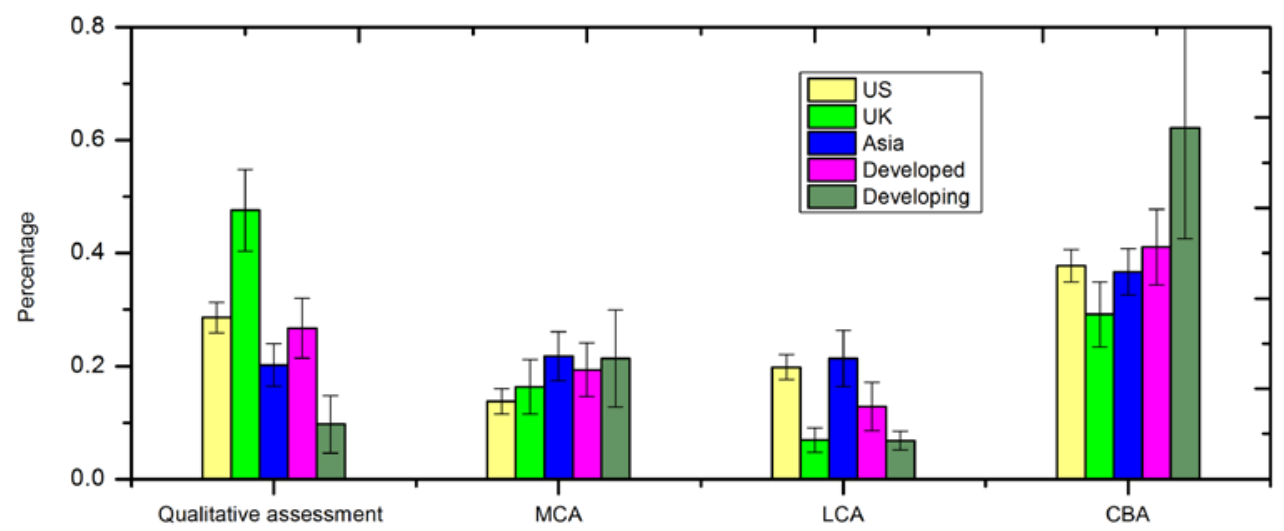

Figure 3. Sustainability evaluation method usage (MCA=multi-criteria analysis; LCA=life cycle assessment; CBA=economic cost benefit analysis).

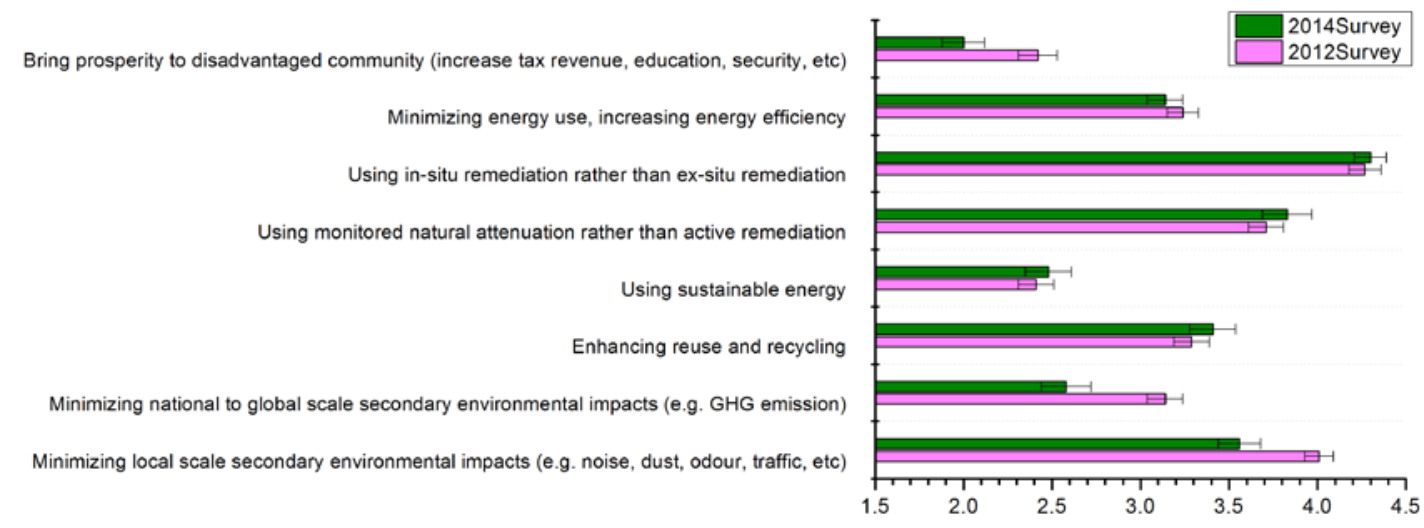

Figure 4. Comparison of the adoption of sustainable remediation practices in the US between 2012 and 2014.

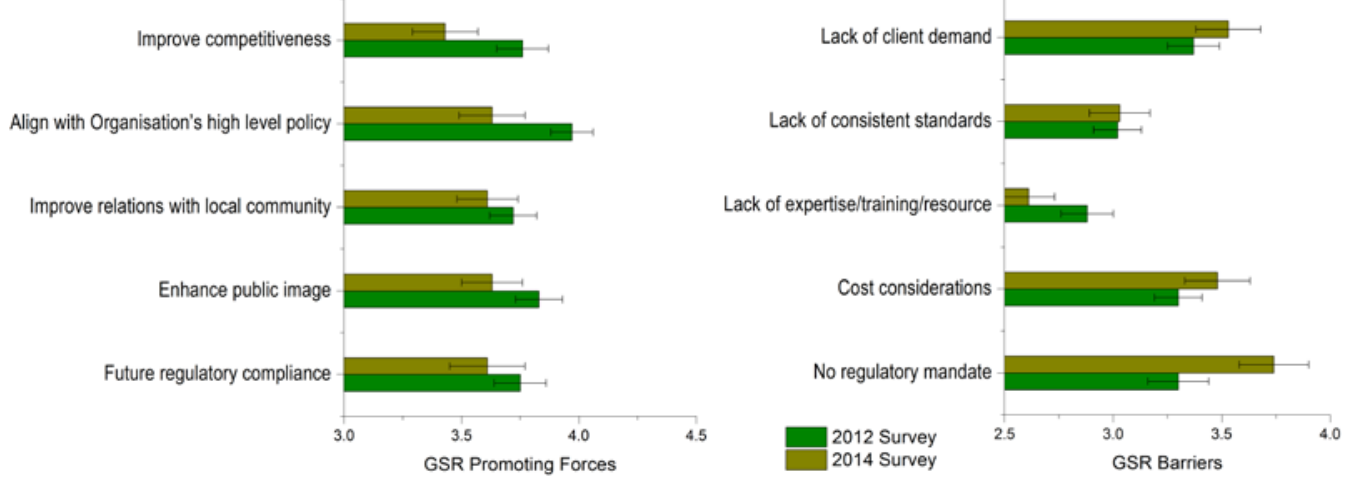

Figure 5. Comparison of sustainable remediation promoting forces and barriers in 
the US between 2012 and 2014.

Page 28 of 28 